\title{
Design and Simulation of a flyback converter for Solar Energy Powered DC loads
}

\author{
Deepthi Chennampalli, Dr.G.S.Anitha \\ ${ }^{I}$ M.tech, Power Electronics R.V. College of engineering Bengaluru, India \\ ${ }^{2}$ Associate Professor, Electrical \& Electronics Engineering R.V. College of engineering Bengaluru, India
}

\begin{abstract}
Due to rapid increase in the production and use of DC appliances it has become a necessity and important to use a converter which can rectify the AC power and can deliver the exact amount of power necessary for the loads to run by either stepping up or stepping down the input power. This paper shows the simulation and design of a flyback converter based on the user specifications
\end{abstract}

Keywords: Solar energy, flyback converter, DC loads

\section{Introduction}

The cost of limited conventional energy sources is rising rapidly. Besides the cost, the adverse impact on environment demands adopting of renewable energy. Noteworthy advantage of distributed energy sources such as solar PV systems is their capability to bestow sustainable electrical energy without harming environment. This becomes even more significant in areas where the conventional power grid has not penetrated. Being the distributed energy source it can be located near the loads. Utilization of solar energy has increased exponentially in last few years. Solar being the major renewable energy source in tropical countries like India necessitates research work for harvesting maximum power from it. The key to sustainable development is improvement in efficiency of harvesting renewable sources and effective use[1].

\section{Motivation and Objective}

DC appliances have become so popular these days due to their low consumption of power and long lasting capability. Research is going on in power electronics field regarding the SMPS converters. They can be both DC-DC converters or AC-DC converters with rectification and filtering. According to the international standards the electro magnetic interference and THD are to be limited to certain level. So extra measures are taken to regulate the EMI and to control the THD by using fast response switching devices like MOSFET and IGBT. SMPS circuits like buck, boost, buck-boost, flyback converters are used to get the regulated output for DC appliances Flyback topology is more famous among other SMPS converters due to its simple circuit and isolation between the input voltage and the output voltage. Its input may be a rectified DC voltage from AC mains supply or a direct DC input voltage. Its output power range can vary from different values to a maximum of $100 \mathrm{~W}$. Due to its simple circuitry and high efficiency for low power outputs it use has increased tremendously in areas requiring regulated low DC power outputs.

\section{Principle and Working of Fly back Converter}

In Figure. 1 the circuit diagram of a fly-back converter is shown. Input supply to the SMPS circuit may be a rectified voltage from any AC supply. An isolation transformer is used to isolate the source side and the load side. As the SMPS circuit operates with high switching frequency, the input voltage even though is not regulated is considered regulated at the output side due to its high frequency response. Switching devices like MOSFET and IGBT are used for fast responses and to maintain constant output voltage [2].

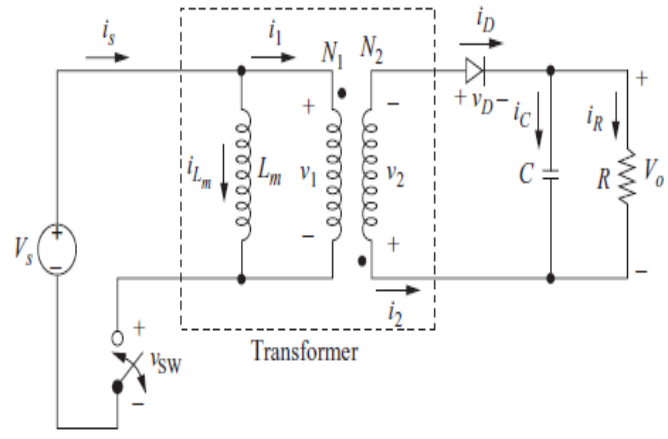

Figure 1: Basic Topology of Flyback Converter 


\section{A. Analysis for the Switch open}

When the switch opens (Fig. 2), as there is no return path for the current in the primary side the energy from the source side is transferred to the load side. As the diode is forward biased this would be possible. The current on the secondary side is transferred to the load via the short circuited diode

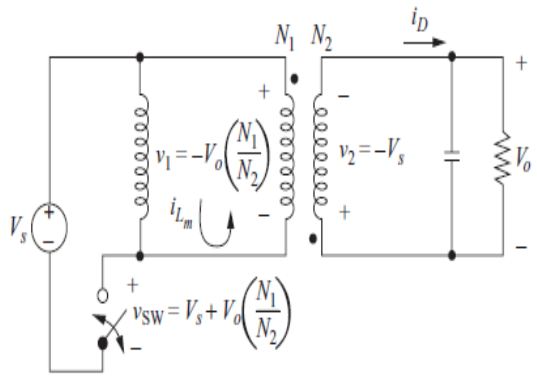

Figure 2: Circuit for switch open

\section{B. Analysis for the switch closed}

When the switch is closed there is a return path for current in the primary side. The primary side inductor gets energised linearly. But due to the reverse biased diode the secondary side inductor cant be energized. So the current through it will be zero.

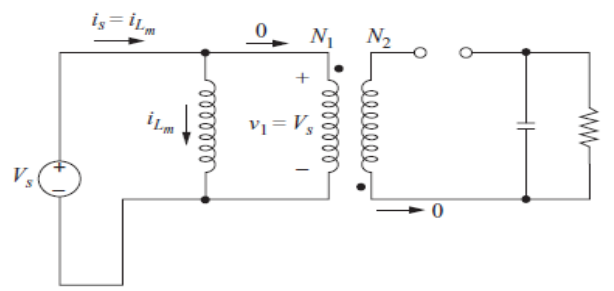

Figure 3: Circuit for switch closed

\section{Matlab simulation block of flyback converter}

The simulink model of the flyback converter used for solar energy powered DC loads is shown in figure 4. The AC power generated using the solar panels is first converted into DC power by the diode rectifier and then stepped down to lower voltage levels using the flyback converter.

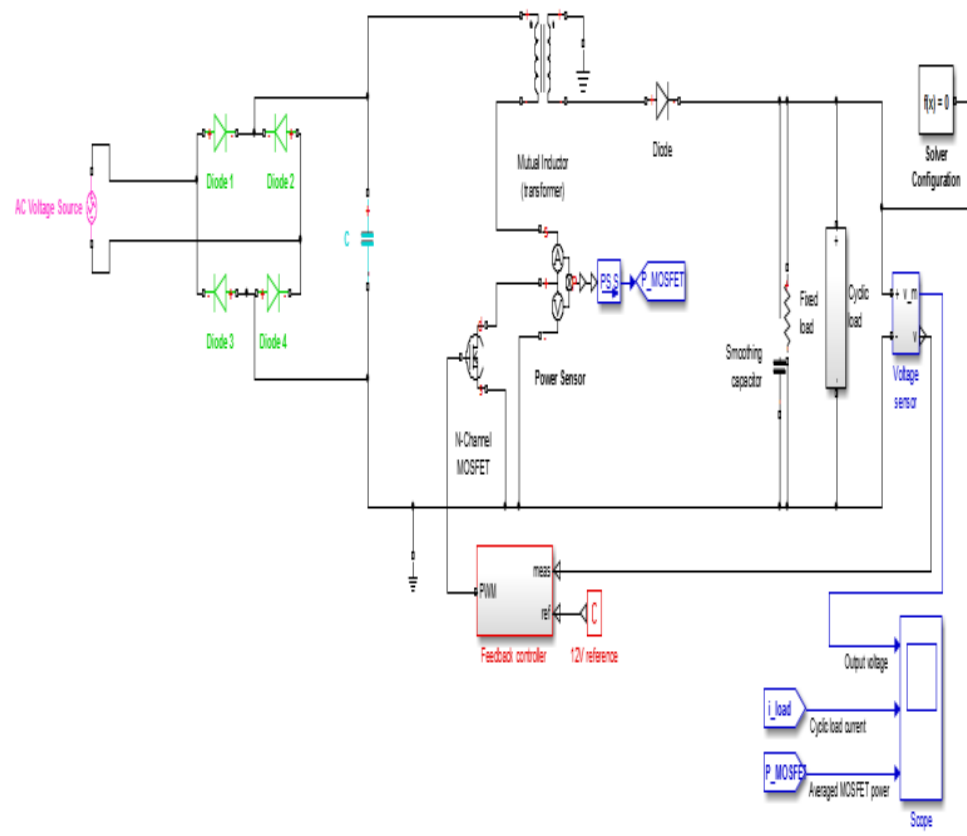

Figure 4: Simulation block of Flyback converter 


\section{Simulation Design and results}

The flyback converter is to be designed for the requirements as tabulated below:

\begin{tabular}{|l|c|}
\hline Parameter & Value \\
\hline Input Volage & $230 \mathrm{~V}$ \\
\hline Output Power & $100 \mathrm{~W}$ \\
\hline Output Voltage & $12 \mathrm{~V}$ \\
\hline Efficiency & $85 \%$ \\
\hline
\end{tabular}

Table 1: Design specifications of the Flyback converter follows:

After designing the flyback converter for the above given specifications the results obtained are as

Figure 5 shows the waveforms of output power, output voltage and output current of the flyback transformer designed to meet the specifications tabulated in table

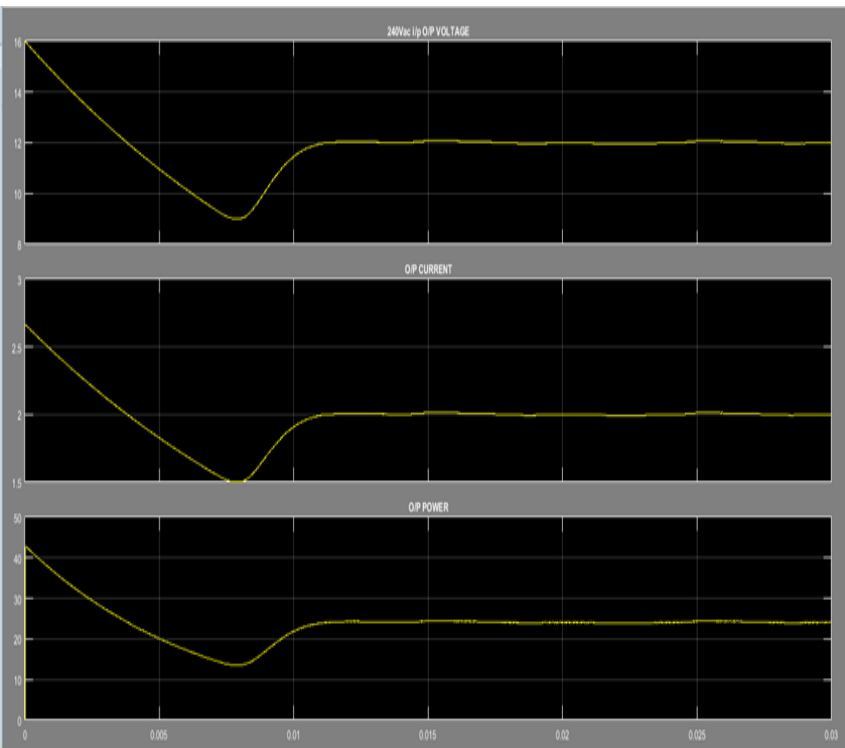

Figure 5: Resulting waveforms of output voltage, output current, output power of the simulink model of flyback converter respectively

\section{Conclusion}

The basic working of the converter, its design procedure, the simulation block and its results are mentioned in this paper. The simulation results are used to further carry out this project to hardware level. This flyback converter is mainly intended to be used in the household and rural areas where mostly DC appliances are in use.

\section{References}

[1]. G.Boyle, "Renewable Energy, Power for a sustainable future", Oxford University Press in association with the Open University, second edition, 2004.

[2]. Rakesh Maurya1, Punnaiah Gunturu \& Shaikh Mo," Simulation and Design of an Integrated Fly Back Converter for Uninterruptible Power Supply",IEEE Trans, Vol 3,2010.

[3]. W. Tang, Y. Jiang, G. C. Hua, and F. C. Lee," Power Factor Correction With Flyback Converter Employing Charge Control", IEEE Trans, 1993.

[4]. K. Umamaheswari , V. Venkatachalam "Single Phase Converters for Power Factor Correction with Tight Output Voltage Regulation" International Journal of Emerging Technology and Advanced Engineering, Volume 3, Issue 2, February 2013

[5]. Y. M. Liu and L.K.Chang, "Single-stage soft-switching AC-DC converter with input current shaping for universal line applications," IEEE Trans. and.Electron.,vol.56, no.2, pp.467-479, Feb.2009.

[6]. Tzuen-Lih Chern ,Li-Hsiang ,Liu Ping-Lung Pan ,Yi-Jie Lee” Single-Stage Flyback Converter for Constant Current Output LED Driver with Power Factor Correction”, IEEE Trans. and.Electron.,vol.56, no.2, pp.467-479, Feb.2009.

[7]. Himanshu K Patel "Flyback Power Supply EMI Signature and Suppression Techniques", IEEE Trans. and.Electron.,vol.56, no.2 , Feb 2009 